\title{
Descricão comparativa versus Fundamentação: o quinto capítulo de Para Além de Bem e Mal: "Contribuição à história natural da moral'"*
}

\author{
Marco Brusotti**
}

Resumo: Para além de bem e mal, sobretudo o quinto livro, é um texto chave no que diz respeito ao programa nietzschiano de uma "história natural da moral". Em oposição ao projeto de fundamentação da moral que caracterizou a suposta ciência da moral até então, Nietzsche propõe ali, por um lado, um trabalho de reunião de material etnográfico e histórico, realizado a partir de uma análise comparativa das diversas morais, e, por outro, a elaboração de uma tipologia da moral capaz de nos revelar as configurações mais assíduas e recorrentes nos diversos sistemas morais. $\mathrm{O}$ que norteia esse programa de renovação da ciência da moral é a ideia de que é preciso retraduzir o homem de volta à natureza, de modo que as diversas configurações morais, heterogêneas e historicamente situadas, poderiam ser interpretadas psicologicamente: elas são uma semiótica dos afetos. Nesse sentido, aspectos psicológicos e histórico-naturais convergem em torno de um tema central: a moral do rebanho e os instintos que nela se expressam. A essa moral Nietzsche contrapõe seu problemático projeto de disciplinação e cultivo de um tipo superior.

Palavras-chave: moral - ciênca - tipologia - história - homo natura

\footnotetext{
* Este trabalho foi financiado pelo projeto de pesquisa "Nietzsche: Edition und Rezeption" (PRIN 2009, MIUR, Itália). Publicado originalmente em: "Vergleichende Beschreibung versus Begründung. Das fünfte Hauptstück: ,zur Naturgeschichte der Moral““. In: Marcus Andreas Born (ed.), Friedrich Nietzsche - Jenseits von Gut Und Böse. De Gruyter: Berlin, p. 111-130 (2014). Tradução de William Mattioli. Revisão técnica de Rogério Lopes.

** Professor da Universidade de Salento/Lecce, Itália, e na Universidade Técnica de Berlin, Alemanha. Correio eletrônico: brusotti@hotmail.com
} 
Brusotti, M.

Em 1887, um ano após Para além de bem e mal, um artigo sobre "A ciência positiva da moral na Alemanha" é publicado na Revue philosophique. ${ }^{1}$ A ocasião é fornecida pela publicação da Ética de Wilhelm Wundt em outubro de 1886. ${ }^{2} \mathrm{O}$ autor, Émile Durkheim, vê neste livro a expressão de um movimento característico da Alemanha e demonstra sua estima, entre outros, por intelectuais familiares a Nietzsche, como os juristas Rudolf von Jhering e Albert Hermann Post, além do próprio Wundt. Durkheim chega à conclusão de que uma ciência da moral ainda estaria em sua fase inicial, entre outras razões, pelo fato de que o material etnológico até então analisado ainda seria muito incompleto. ${ }^{3}$

É com uma avaliação semelhante que Nietzsche inicia "Contribuição à história natural da moral", o quinto capítulo de Para além de bem e mal: o que se chamaria hoje de "ciência da moral" seria "ainda jovem, incipiente, tosca e rudimentar" (JGB/BM 186, KSA 5.1054). Os filósofos da moral, para os quais o que importava era apenas uma fundamentação da própria moral, "eram mal informados [...] a respeito de povos, tempos e eras", eles conheciam "os fatos morais apenas grosseiramente, num excerto arbitrário ou compêndio fortuito, como moralidade do seu ambiente, de sua classe, de sua igreja, de sua época, de seu clima e seu lugar" (JGB/BM 186, KSA 5.105). Por isso valeria, agora e "por muito tempo", descrever as muitas e heterogêneas morais de modo comparativo; partindo de uma

1Cf. DURKHEIM, Émile. "La science positive de la morale en Allemagne", In. Revue philosophique 24, 1887. Sobre o famoso artigo de Durkheim, cf. TREIBER, Hubert. Zur Genealogie einer "science positive de la morale en Allemagne". Die Geburt der "r(é)ealistischen Moralwissenschaft" aus der Idee einer monistischen Naturkonzeption. In. Nietzsche-Studien 22, Berlin/New York: de Gruyter, 1993, 165-221.

2 Para Para Para Além de bem e mal já havia sido publicado em 1886. Nada indica que Nietzsche tenha lido o artigo de Durkheim. Ele conhecia, porém, a Revue philosophique e a obra de seu fundador e então editor, Théodule Ribot.

3 Cf. DURKHEIM, Émile. Op cit., p. 283 s.

4 Todas as passagens das obras publicadas de Nietzsche foram traduzidas por Paulo César de Souza.

18 | Cad. Nietzsche, Guarulhos/Porto Seguro, v.37, n.1, p. 17-43, 2016. 
"reunião de material", esse aforismo programático pretende avançar gradualmente rumo a uma "tipologia da moral". O primeiro estágio, que "unicamente se justifica por enquanto", implica portanto numa "reunião de material, formulação e ordenamento conceitual de um imenso domínio de delicadas diferenças e sentimentos de valor que vivem, crescem, procriam e morrem" (JGB/BM 186, KSA 5.105). De fato, "talvez tentativas de tornar evidentes as configurações mais assíduas e sempre recorrentes dessa cristalização viva" seriam justificadas já nesse reunir e ordenar o material - "como preparação para uma tipologia da moral" (JGB/BM 186, KSA 5.105). Mas o essencial da próxima fase preparatória consistiria numa “descrição" e "comparação", na "tarefa da descrição, aparentemente insignificante e largada ao pó", mas para a qual "talvez os sentidos e os dedos mais finos não bastassem!"” (JGB/BM 186, KSA 5.105) Somente com essa tarefa comparativa estaríamos no início de uma "tipologia da moral" (JGB/BM 186, KSA 5.105), que não parece estar na ordem do dia.

\section{Descrição contra fundamentação}

Descrição (mais tipologia) constitui aqui a alternativa e a oposição à "fundamentação da moral" (JGB/BM 186, KSA 5.105). Essa reivindicação filosófica tradicional não poderia ser mantida. Algo como $a$ moral não pode valer como algo "dado" (JGB/BM 186, KSA 5.105), e tampouco seria permitido sonhar com uma "ciência" que a fundamentasse. Um ano após a publicação de Para além de bem e mal, a segunda edição de $A$ gaia ciência esclarece que, a partir da comparação das morais, não se pode extrair conclusões universalistas nem relativistas: de um certo "consenso dos povos, ao menos dos povos domesticados, a respeito de certos princípios morais", não se pode deduzir a "incondicional obrigatoriedade destes para cada um de nós" ( $F W / G C 345, \mathrm{KSA} 3.577)$; igualmente ilícito seria concluir "pela não-obrigatoriedade de toda moral" a partir 
Brusotti, M.

da "verdade de que em povos diversos as avaliações morais são necessariamente diversas"; "duas conclusões igualmente infantis" (FW/GC 345, KSA 3.577). A descrição comparativa das diversas morais não tem qualquer relação com a pretensão de fundamentação de uma única moral.

Em Para além de bem e mal 186, parece que aquilo de que se trata é sobretudo o conhecimento dos fatos; a descrição comparativa das morais não é diretamente uma tarefa filosófica. Estaria Nietzsche compartilhando da tendência positivista em separar a ética da filosofia e atribuí-la à ciência, mesmo que, diferentemente de Durkheim, essa ciência não seja necessariamente a sociologia? O primeiro aforismo do capítulo seguinte (o sexto) opõe-se claramente à tendência positivista de substituir a filosofia pelas ciências. E já em Para além de bem e mal 186 é dito que "os verdadeiros problemas da moral [...] emergem somente na comparação de muitas morais" (JGB/BM 186, KSA 5.105). Justamente por isso, toda ciência da moral até então foi somente uma suposta ciência, pois nela ainda faltava "o problema da própria moral". A "fundamentação da moral" era apenas "uma forma erudita da ingênua fé na moral dominante", "uma espécie de negação de que fosse lícito ver essa moral como um problema". É diante dessa questão filosófica que Nietzsche pretende se colocar agora: o "exame, questionamento, análise, vivissecção" (JGB/BM 186, KSA 5.105) da fé na moral dominante, até então deixado de lado por aqueles filósofos, está finalmente posto em pauta.

$\mathrm{O}$ aforismo 186 de Para além de bem e mal convida repetida e veementemente à modéstia e recusa não somente das pretensões de fundamentação dos filósofos da moral como presunçosas, mas também as propostas contemporâneas de uma ciência positiva: "Considerando aquilo que designa, a expressão 'ciência da moral' resulta demasiado arrogante e contrária ao bom gosto: o qual é sempre gosto antecipado pelas palavras mais modestas" (JGB/BM 186, KSA 5.105). Nietzsche sugere aos seus leitores que abdiquem 
da expressão "ciência da moral" e escolham uma menos pretensiosa. Se (somente) a "tipologia", que deve resultar das investigações comparativas, merece o nome de "ciência da moral" é algo que não se deixa deduzir do texto. A princípio, trata-se somente de reunir e ordenar o material; é verdade que alguns passos além "talvez" já possam ser dados; mas a tipologia ela mesma ainda não se encontra na agenda.

No último capítulo, “O que é nobre?", Nietzsche certamente não é modesto: “Numa perambulação pelas muitas morais, as mais finas e as mais grosseiras, que até agora dominaram e continuam dominando na Terra, encontrei certos traços que regularmente retornam juntos e ligados entre si" (JGB/BM 260, KSA 5.208). Nietzsche realmente pretende já ter "percorrido" " $a$ ", isto é, todas as morais existentes até então? Ou ele está aquém daquilo que havia reivindicado no início de "Contribuição à história natural da moral"? Uma "perambulação" soa certamente mais descompromissado que uma "reunião de material". Apesar disso, Nietzsche já extrai dessa "perambulação" conclusões fortemente tipológicas: ela conduz a duas séries de traços regularmente ligados entre si; e dessas séries já resultam então, para ele, "dois tipos básicos": "moral dos senhores e moral de escravos" (JGB/BM 260, KSA 5.208). A comparação transcultural culmina, portanto, numa "diferença fundamental", numa dicotomia, mesmo que os tipos, "em todas as culturas superiores e mais misturadas" (JGB/BM 260, KSA 5.208; cf. GM/GM, I, 16, KSA 5.285) não ocorram de modo puro, mas são mediados e fundidos uns com os outros de vários modos; a "mediação", a "confusão" ou ainda a "dura coexistência" desses dois tipos fundamentais, "até mesmo no mesmo homem, no interior de uma só alma" (JGB/BM 260, KSA 5.208), são aqui a regra. A reflexão acerca da questão "o que é nobre?" deve ajudar esse homem a reconhecer em si mesmo os elementos de ambos os tipos, a promover uns e a combater os outros. ${ }^{5}$

5 Cf. sobre isso a carta de Nietzsche a Heinrich Köselitz de 23 de julho de 1885; KSB 7, 68s.

Cad. Nietzsche, Guarulhos/Porto Seguro, v.37, n.1, p. 17-43, 2016. 
Brusotti, M.

\section{As muitas morais e os dois tipos básicos}

Os aforismos 186 e 230 de Para além de bem e mal descrevem procedimentos semelhantes. Seguindo a) uma demorada e cuidadosa reunião de material etnológico e histórico (JGB/BM 186, KSA 5.105) e uma "perambulação" pelas morais até então existentes (JGB/BM 260, KSA 5.208), b) uma morfologia tornará evidentes "as configurações mais assíduas e sempre recorrentes" (JGB/BM 186, KSA 5.105), ou seja, Nietzsche encontra "traços" que "regularmente retornam juntos" e estão "ligados entre si" (JGB/BM 260, KSA 5.208); disso resulta c) uma "tipologia da moral" (JGB/BM 186, KSA 5.105) supra-cultural e uma oposição entre dois "tipos fundamentais" (JGB/BM 260, KSA 5.208). Nietzsche designa os tipos de moral (moral dos senhores e moral de escravos) segundo os tipos de homem correspondentes. Que se trata também de tipos de homem não é sequer sugerido no parágrafo 186: nada consta no aforismo sobre a "tipologia" - nem mesmo sobre o que se deve entender por "tipo". Tampouco nos é dito que a tipologia, assim como a descrição das morais, é apenas um estágio preparatório, a saber, para uma nova determinação de valores. Somente o 260 deixa claro que a "tipologia" é valorativamente carregada e deve fornecer uma resposta à pergunta "o que é nobre?", estando, portanto, essencialmente ligada à nova determinação de valores. Este papel preparatório é claramente apresentado em Para além de bem e mal: "estabelecer e colocar em fórmulas [...] algum vasto campo de valorações" faz parte da tarefa dos "trabalhadores filosóficos"; abreviar tudo que é longo [...] e subjugar o passado inteiro" seria apenas "trabalho prévio" (JGB/BM 211, KSA 5.144). Com efeito, a verdadeira atividade sintética seria a criação de novos valores pelos "autênticos filósofos" (JGB/BM 211, KSA 5.144).

A História natural do homem [Naturgeschichte des Mensche] de Hellwald - Nietzsche anota o título na época de composição de Para 
Além de bem e mal ${ }^{6}$ - é uma apresentação, dividida por continentes, das matrizes não européias. Hellwald, que se orienta também pelas teses de Darwin, começa com a Austrália, o continente no qual, segundo a concepção da época, vivem as tribos "mais primitivas". A divisão geográfica contém, portanto, um momento evolucionista. Apesar disso, o livro mostra que, na época de Nietzsche, uma história natural podia ser construída de modo primariamente sincrônico. $\mathrm{O}$ momento diacrônico não necessariamente precisa prevalecer.

A “comparação de muitas morais", no parágrafo 186, parece conduzir a um arranjo sincrônico do material etnológico e histórico reunido. Nada aqui vai contra a ideia de que a "tipologia" é somente um tableau. A abordagem comparativa de Nietzsche, porém, se dá não apenas de modo sincrônico: "Contribuição à história natural da moral" vê um tipo de moral alcançar o predomínio através de uma bem sucedida "rebelião escrava na moral", através de uma "inversão dos valores" (JGB/BM 195, KSA 5.116). No mais tardar na Genealogia da moral, a hipótese transcultural de dois tipos básicos de moral é o que está na base da história da gênese. Tipologia e gênese estão profundamente ligadas. Os dois tipos básicos não são, aos olhos de Nietzsche, apenas um instrumento de classificação, isto é, não são meramente categorias analíticas nas quais o material histórico e etnológico poderia ser agrupado numa investigação mais detalhada. Antes, eles são forças históricas efetivas, que lutam entre si num conflito que já dura um milênio; eles são, por assim dizer, os veículos da história e, enquanto tais, objeto de uma investigação histórico-genealógica.

A comparação entre os textos 186 e 260 mostra que Para Além

6"Hellwald, História natural do homem" (Nachlass/FP 39 [21]; KSA 11.627). Cf. HELLWALD, Friedrich Anton Heller von. Naturgeschichte des Menschen, Stuttgart: Francke, 1882.). Deste autor, Nietzsche já havia lido a História cultural em seu desenvolvimento natural até o presente (1875) (cf. Nachlass/FP 5 [58]; KSA 8.56s). Em sua biblioteca encontra-se o segundo volume de Die Erde und ihre Völker. Ein geographisches Hausbuch (2. edição, 1877/78). Cf. ainda a carta de Nietzsche a Franz Overbeck de 8 de julho de 1881 (KSB 6.100s). 
Brusotti, M.

de bem e mal mede com duas medidas. O 186 pretende dissuadir os contemporâneos da proposta de uma fundamentação da moral: à incipiente "ciência da moral" é prescrita aqui uma fase preparatória de modesto e paciente agrupamento e ordenação de material, antes que possa ser estabelecida uma tipologia que, enquanto tarefa, é menos ambiciosa que a inexequível fundamentação da moral, mas que, frente ao estado atual do conhecimento, é ainda demasiadamente exigente. Como dito, ela não é determinada aqui de modo mais claro. No último capítulo, ao contrário, a tarefa tipológica é resolvida pelo próprio Nietzsche, e para este fim basta-lhe simplesmente uma "perambulação" pelas morais até então existentes.

Nesse contexto, uma violenta redução de complexidade ocorre, a qual, apesar de todas as diferenças, lembra a antropologia evolucionista da época. Tylor, Lubbock e outros reúnem de modo comparativo materiais das mais diversas culturas e os ordenam numa suposta escala de progresso cultural. Os antropólogos evolucionistas destituem fenômenos históricos e etnológicos de sua especificidade cultural ao transformá-los aleatoriamente em varáveis intercambiáveis no interior da respectiva "escala cultural" universal. Nietzsche se apoia, mesmo que com muitas ressalvas, na antropologia envolucionista, mas, para ele, o que deve resultar das análises comparativas não são tanto escalas culturais, mas sim tipos (mesmo que acentue, assim como os evolucionistas, a estranheza de culturas passadas). Desse modo, a abordagem com a qual ele despreza peculiaridades culturais corresponde sobretudo à sua tendência tipológica; ela constitui um poderoso contra-peso com relação à tendência historicizante, etnológica, limitando-a e relativizando-a ${ }^{7}$. A larga experiência

7 Também na Genealogia da moral há uma tensão entre a tipologia e o caráter (supostamente) documentário da abordagem histórica proclamada por Nietzsche (cf. sobre esta última GM/ GM, Prólogo, 7, KSA 5.254). Na Genealogia, a nota anexada à primeira dissertação está para a dissertação mesma assim como o parágrafo 186 de Para além de bem e mal está para o 260: o que é desenvolvido no texto principal sem ressalvas, é colocado na nota ainda como tarefa a ser realizada no contexto de um ambicionado programa de pesquisa coletivo, no qual o material

24| Cad. Nietzsche, Guarulhos/Porto Seguro, v.37, n.1, p. 17-43, 2016. 
histórica e cultural, que inclui círculos culturais estrangeiros e sublinha sua distância (descobrimos também uma Grécia que nos é estranha), deve expandir o horizonte do presente, deve ajudar os espíritos livres a abrir mão daquilo que tomam por autoevidente e a assumir um ponto de vista supraeuropeu ${ }^{8}$. $O$ que finalmente surge daí é, porém, algo diferente: uma tipologia binária (supostamente) válida supraculturalmente, em conjunto com a pretensão de ter redescoberto e por assim dizer desenterrado a moral dos senhores que se tornara estranha aos modernos. Enquanto a "moral de escravos" é tão familiar ao presente que ela é tida como $a$ moral pura e simplesmente, a moral nobre é, hoje, "difícil de ser percebida, e também desenterrada e descoberta" (JGB/BM 260, KSA 5.208). Aos olhos de Nietzsche, a moral nobre permaneceu estranha aos modernos, pois somente as naturezas superiores são capazes de reconhecer aquilo que lhes é afim no mundo do passado. Por conseguinte, a estranheza cultural se funda, em última instância, na estranheza tipológica. Nessa suposição básica se encontra um limite essencial da abordagem de Nietzsche. A multiplicidade das morais e a tarefa de se orientar nesse âmbito são vistas pelo filósofo de modo claro, mas ele tende a preterir as dificuldades: com efeito, ele se coloca sobretudo a tarefa de trazer novamente à tona um tipo básico reprimido.

\section{História natural da moral e psicologia da moral}

A primeira parte do aforismo 186 pode ser compreendida como manifesto de uma "história natural da moral", apesar dessa expressão (ou apenas a palavra "história natural") não ocorrer aqui nem tampouco

necessário ainda deve ser reunido e avaliado. Cf. sobre isso BRUSOTTI, Marco. "Naturalismus? Perfektionismus? Nietzsche, die Genealogie und die Wissenschaften". In. HEIT, Helmut/ABEL, Günter/BRUSOTTI, Marco (Hrsg.). Nietzsches Wissenschaftsphilosophie: Hintergründe, Wirkungen und Aktualität, Berlin/Boston: de Gruyter, 2011, p. 91-112.

8 Cf. BRUSOTTI, Marco. "Europäisch und über-europäisch". Nietzsches Blick aus der Ferne. In. Tijdschrift voor Filosofie 66, 2004, p. 31-48

Cad. Nietzsche, Guarulhos/Porto Seguro, v.37, n.1, p. 17-43, 2016. 
Brusotti, M.

no resto do capítulo. Se os aforismos que se seguem apresentam estágios preparatórios para algo como uma verdadeira "ciência da moral" que deve se diferenciar das supostas "ciências da moral" anteriores, trata-se, porém, de uma outra questão. "Contribuição à história natural da moral" não fornece uma reunião de material etnológico e histórico; o programa de pesquisa esboçado no aforismo introdutório - a "comparação de muitas morais" - permanece, assim, não realizado. Após esse texto programático, o bastante heterogêneo capítulo quinto parece carecer de especificidade: aforismos inteiros podem ser associados à história natural, mas com frequência não em maior medida do que os aforismos de outros capítulos.

É interessante notar que, inicialmente, o capítulo tinha outro título: foram considerados títulos como "psicologia da moral" ( $K G W$ IX 5, 173), "contribuição à psicologia da moral” (KGW IX 5, 174), "apontamentos de um psicólogo da moral" ou ainda "solilóquio de um psicólogo" (KGW IX 5, 174). Somente em um plano posterior o título "apontamentos de um psicólogo da moral" foi riscado e substituído por "contribuição à história natural de moral" ( $K G W$ IX $5,159)$. Se comparamos esboços de títulos e de estrutura, vemos que Nietzsche, durante a gênese do texto, considera diferentes empregos do termo "história natural". Por exemplo, para o capítulo que, na versão final, leva como título apenas "nós, eruditos", surge a variante "contribuição à história natural do erudito" (KGW IX 2, 78; Nachlass/FP 1 [187], KSA 12.52). Mais importante é o fato de que as expressões "contribuição à história natural do espírito livre" e "contribuição à história natural do homem superior" (KGW IX 5, 172) eram reiteradamente consideradas, e não meramente como títulos para um capítulo, mas título para a obra, ou seja, como possíveis alternativas a Para além de bem e mal. Inicialmente, Nietzsche tinha em vista, de acordo com o que vimos, sobretudo a "história natural" do homem superior, do espírito livre ou ainda do erudito; mas finalmente a expressão encontrou sua formulação definitiva 
- e a única em Para além de bem e mal - como título do capítulo sobre a "psicologia da moral". Na medida em que Nietzsche inclui "o homem, cruamente e sem metáfora, entre os animais" (JGB/BM 202, KSA 5.124), as considerações sobre psicologia da moral se deixam compreender sem qualquer dificuldade como considerações histórico-naturalistas.

Se deixarmos de lado o aspecto terminológico, "o mais novo dos métodos filosóficos" defendido em Humano, demasiado humano, uma "filosofia histórica, que não se pode mais conceber como distinta da ciência natural" (MA I/ HH I 1, KSA 2.23), já pode ser considerado como história natural, como uma história evolutiva do homem e de seus sentimentos e representações morais que não pode ser escrita sem o apoio das ciências da natureza. Nietzsche não se encontra sozinho com seu projeto "histórico-naturalista". Sem listar todas as conexões históricas, começando com o amigo de Nietzsche, Paul Rée, até o já mencionado Hellwald, lembremos aqui apenas da reivindicação de Darwin de ter sido o primeiro a abordar a pergunta pela origem do sentimento moral, da obrigação, "exclusivamente do ponto de vista da história natural"9. Durante os trabalhos para publicação de Aurora, Nietzsche leu a História da moral europeia de Lecky. Na tradução utilizada por Nietzsche, o primeiro capítulo da obra, que é teórico, leva o título "A história natural dos costumes"10.

Nas publicações de Nietzsche, a expressão "contribuição à história natural da moral" é antecipada somente uma vez: um aforismo de Aurora é intitulado: "Contribuição à história natural do dever e do direito" (M/A 112, KSA 3.100). ${ }^{11} \mathrm{O}$ título "contribuição à

9 DARWIN, Charles. Die Abstammung des Menschen und die geschlechtliche Zuchtwahl. Dritte gänzlich umgearbeitete Auf lage, Stuttgart: E. Schweizerbart'sche Verlagshandlung, Vol I, 1875, p. 126.

10 Cf. LECKY, William Edward Hartpole. Sittengeschichte Europas von Augustus bis auf Karl den Grossen, Bd. 1, Leipzig/Heidelberg: C.F. Winter'sche Verlagshandlung, 1879, p. 1-144.

11 Nos escritos publicados por ele, Nietzsche havia utilizado até então, além de Aurora, apenas uma vez a expressão "história natural", num aforismo de Opiniões e sentenças diversas: "Como 
Brusotti, M.

história natural da moral" anuncia, de certo modo, o próximo livro de Nietzsche, Contribuição à genealogia da moral. Se a história natural antecipa a genealogia é, porém, uma questão que conduz facilmente ao erro. Com efeito, as expressões "genealogia" e "história natural" têm em comum o fato de Nietzsche fazer uso delas de modo muito parcimonioso. É apenas na recepção que o termo "genealogia" se torna uma designação para o método próprio de Nietzsche. ${ }^{12}$ A palavra "história natural" desempenhou de fato um papel especial na gênese do texto, mas em Para além de bem e mal a expressão ocorre somente no título do quinto capítulo - e em nenhum outro lugar. Nesse sentido, não se impõe interpretar o desenvolvimento conceitual entre os dois escritos como uma transição de um método histórico-naturalista para um método genealógico.

\section{Temas básicos de "contribuição à história natural da moral"}

Uma história natural sistemática não está presente no quinto capítulo, nem mesmo em esboço: os aforismos não são senão

deve ser narrada a história natural" (VM/OS 184, KSA 2.460). Sobre as leituras de Nietzsche em história natural, indica-se uma contribuição do autor deste artigo que será publicada em breve.

12 Além do título da obra, a expressão "Genealogie der Moral" não ocorre em nenhum outro lugar! Apenas duas vezes fala-se em "Moral-Genealogie". As expressões "Genealogie" e "genealogisch" designam na maioria das vezes os oponentes de Nietzsche e suas hipóteses: há uma crítica a "uma espécie contrária e perversa de hipótese genealógica, sua espécie propriamente inglesa" (GM Prólogo 4), à tosca "genealogia da moral" (GM I 2) dos "genealogistas da moral ingleses" (GM Prólogo 4) assim como dos "genealogistas da moral até então" (GM II 12), dos "genealogistas da moral" que "não valem nada" (GM II 4), dos "ingênuos genealogistas da moral e do direito" (GM II 13). Nietzsche não tem, portanto, o menor interesse em designar apenas a si mesmo como "genealogista da moral" e qualificar apenas suas próprias hipóteses acerca da origem como "genealógicas". Além disso, ele nunca fala em um método genealógico, mas apenas em um "método histórico" (GM II 12 e GM II 13); os "métodos mais corretos" que ele quis, em vão, atribuir a Paul Rée, exigiriam a "direção da efetiva história da moral" (GM Prólogo 7). Portanto, Nietzsche não distingue entre genealogia e história, mas, antes, entre si mesmo, o bom genealogista, que se vale o método histórico correto e se dedica à efetiva história da moral, e os genealogistas ruins, que não o fazem.

28 | Cad. Nietzsche, Guarulhos/Porto Seguro, v.37, n.1, p. 17-43, 2016. 
"apontamentos" para a história natural da moral, e para a psicologia da moral. Uma investigação genética do passado moral não constitui ali o foco principal. Em primeiro plano se encontra, antes, uma crítica ao presente, à época dos "europeus bichos de rebanho" (JGB/BM 199, KSA 5.119) com sua "moral de animal de rebanho" (JGB/BM 202, KSA 5.124); e também o futuro é compreendido a partir de conceitos histórico-naturalistas e mesmo zootécnicos, o tempo de possíveis "tentativas globais de disciplinação e cultivo" (JGB/BM 203, KSA 5.126). O capítulo se encerra com essa visão questionável do futuro. Fazem parte do objeto da história natural, portanto, possíveis futuras morais; estas são mesmo a preocupação principal.

Se compararmos com os outros capítulos, é mais raro nos depararmos, em "contribuição à história natural da moral", com os "encadeamentos de aforismos" característicos de Para além de bem e mal. Os seguintes focos temáticos, porém, podem ser destacados, e com isso podemos reconhecer, grosseiramente, algo como a arquitetura do capítulo. As possíveis morais particulares, heterogêneas e historicamente dadas, podem ser interpretadas psicologicamente: elas são uma "semiótica dos afetos" (JGB/BM 187, KSA 5.107) (A). À variabilidade dos conteúdos corresponde algo como uma forma geral: a "coerção" que exercem sobre o homem as prescrições, em última instância "aleatórias", das morais particulares (B). Apesar de uma "tipologia da moral", segundo o aforismo de abertura, ainda não estar na agenda do dia, também esse capítulo gira em torno de oposições tipológicas (C). Aspectos psicológicos e histórico-naturais convergem no tema central do "rebanho", seus instintos e sua moral (D), e no contra-projeto de Nietzsche, na famigerada "disciplinação e cultivo" de um tipo superior (E).

(A) $\mathrm{O}$ segundo aforismo de "contribuição à história natural da moral" apresenta a tese de psicologia moral segundo a qual a moral seria uma "semiótica dos afetos" (JGB/BM 187, KSA 5.107). $\mathrm{O}$ aforismo programático 23 havia proposto compreender "toda a 
Brusotti, M.

psicologia" como "morfologia e teoria da evolução da vontade de potência" (JGB/BM 23, KSA 5.38). O psicólogo da moral persegue também no quinto capítulo as transformações dos impulsos e afetos: ele esclarece, por exemplo, "por que [...] o impulso sexual foi sublimado em amor (amour-passion)" (JGB/BM 189, KSA 5.110). Mas mesmo que o aforismo de abertura já fale, como que de passagem, de "um mundo cuja essência é vontade de poder" (JGB/BM 186, KSA 5.105), os "apontamentos" sobre psicologia moral que se seguem de nenhum modo dependem desse abrangente e pretensioso conceito. A vontade de potência é meramente mecionada (JGB/BM 198, KSA 5.118 assim como $J G B / B M$ 187, KSA 5.107). O foco, porém, recai sobre aspectos específicos, e uma grande importância é concedida especialmente àquele que, em A gaia ciência, era oposto ao sentimento de poder, a saber, à "pusilanimidade", pois ela é marca essencial da moral de rebanho (sobre a "moral como pusilanimidade", cf. sobretudo JGB/ BM 197 e 198 KSA 5.117, 118).

Com a compreensão da moral como "semiótica dos afetos" [Zeichensprache der Affekte], Nietzsche retoma um dos primeiros aforismos: uma filosofia seria a "confissão pessoal de seu autor" (JGB/ $B M$ 6, KSA 5.19), e este estaria sempre empenhado na realização de uma certa moral. Assim, a especificidade dessa moral poderia ser interpretada de modo funcional: a que ela serve na perspectiva daquele autor? "O que diz uma [...] afirmação sobre aquele que a faz?" (JGB/BM 187, KSA 5.107) Cada uma das morais particulares permitem inferências regressivas aos autores: "também as morais não passam de uma semiótica dos afetos" (JGB/BM 187, KSA 5.107); e "um psicólogo da moral" não apenas as lê "como uma linguagem de símiles e de sinais [Gleichnis- und Zeichensprache] que permite silenciar muitas coisas" (JGB/BM 196, KSA 5.117). Ele deve decifrar essa linguagem de sinais, isto é, deduzir quais são os afetos que se expressam na respectiva moral particular ou no tipo individual.

(B) De fato, toda moral é "um pouco de tirania contra a

$30 \mid$ Cad. Nietzsche, Guarulhos/Porto Seguro, v.37, n.1, p. 17-43, 2016. 
"natureza', e também contra a "razão", mas "natureza' e "natural"" (JGB/BM 188, KSA 5.108) - segundo a suposição de Nietzsche (e que se atente às aspas) - é, muito provavelmente, a existência de normas, quaisquer que sejam, que exercem uma coerção: a "tirania de tais leis arbitrárias" caracteriza a moral em geral. "O essencial e inestimável em toda moral é o fato de ela ser uma demorada coerção", isto é, "que se obedeça por muito tempo e numa direção: daí surge com o tempo, e sempre surgiu, alguma coisa pela qual vale a pena viver na terra" (JGB/BM 188, KSA 5.108). Desse mesmo modo ou de modo análogo fala "o imperativo categórico da natureza, o qual certamente não é 'categórico', como dele exige o velho Kant [...], nem se dirige ao indivíduo [...], mas sim a povos, raças, eras, classes, mas sobretudo ao inteiro bicho 'homem', a o homem" (JGB/BM 188, KSA 5.108). Aqui, algo como um imperativo filogenético é admitido, que se dirige à espécie animal "homem": Nietzsche tem em vista, como ainda veremos abaixo, uma tendência universal à "disciplinação e cultivo" do homem.

Essa tese fundamental sobre a moral em geral - ela lembra o discurso de Zaratustra "Da superação de si mesmo" (Za/ZA, Da superação de si mesmo, KSA 4.146) - é reforçada aqui por um exemplo extraído da "história natural" do espírito livre e de sua "pré-história"; pois a "força" do espírito é uma pré-condição de sua "liberdade", mas ainda não é ela mesma. O fenômeno histórico da escolástica medieval deve atestar que "a escravidão foi, "no sentido mais grosseiro e mais sutil, o meio indispensável também para a disciplina e cultivo espiritual"; a "tirania", o "arbítrio", também "educou o espírito" (JGB/BM 188, KSA 5.108). Assim, a "disciplina e cultivo" espiritual consiste em que, no espírito europeu, mediante uma "disciplinação" [Zucht] de séculos, algo como uma força foi "cultivada". "A prolongada sujeição do espírito, [...] a disciplina que se impôs o pensador, a fim de pensar sob uma diretriz eclesiástica ou cortesã [...] - tudo que há de antirracional nisso revelou-se como 
Brusotti, M.

o meio através do qual o espírito europeu viu disciplinada a sua força" (JGB/BM 188, KSA 5.108). A "natureza" na moral planta "a necessidade de horizontes limitados" e ensina "o estreitamento das perspectivas, e em certo sentido também a estupidez, como condição de vida e crescimento" (JGB/BM 188, KSA 5.108). Assim como as outras virtudes, a liberdade de espírito se originou a partir de seu oposto, da não-liberdade ou sujeição [Unfreiheit], e o espírito forte foi educado mediante uma "extrema e grandiosa estupidez" (JGB/ $B M$ 188, KSA 5.108).

(C) É justamente esse problemático par conceitual "disciplina e cultivo" que representa o conceito mais geral dessa história natural da moral ${ }^{13}$. O duplo sentido de "disciplina" [Zucht $]$ contém, segundo essa concepção, um nexo interno: educação/disciplina moral produz um tipo de homem, o "cultiva". Do ponto de vista da história natural, a moral, na medida em que encontra aceitação, é "disciplina e cultivo": "toda moral que de algum modo dominou sempre foi a disciplina e cultivo de um determinado tipo de homem" (KGW IX 2, 8; cf. Nachlass/FP 1 [239]; KSA 12.63). O tipo de homem é não apenas o "veículo", mas também a meta do tipo de moral denominada de acordo com ele: o tipo de homem cuja "disciplina e cultivo" é praticada por esse tipo de moral. Toda moral dominante pressupõe um "tipo normativo" (KGW IX 2, 7). O "tipo" é, portanto, não apenas uma categoria do observador externo que classifica as morais a partir de um ponto de vista exterior; antes, toda moral trabalha internamente com um tipo que, enquanto ideal regulativo, desempenha uma função essencialmente normativa.

Digno de nota não é apenas o fato de que Para além de bem e mal não define o conceito de "tipo", mesmo quando o autor se propõe

13 Como é sabido, a expressão "disciplina e cultivo" ocorre com frequência nos apontamentos de Nietzsche, por exemplo como título de um capítulo da obra principal nunca escrita (Nachlass/FP 2 [74], KSA 12.95; cf. também 7 [64], KSA 12.318) ou na forma "pensamentos sobre disciplina e cultivo" como subtítulo de outros escritos planejados (Nachlass/FP 36 [55], KSA 11.573 e também 40 [45], KSA 11.652).

32 | Cad. Nietzsche, Guarulhos/Porto Seguro, v.37, n.1, p. 17-43, 2016. 
a elaborar uma "tipologia", mas sobretudo o fato de que aqui - e na verdade na obra como um todo - as coisas mais heterogêneas são chamadas de "tipo": o homem em geral, "o tipo homem" (JGB/ $B M$ 203, KSA 5.126; cf. ainda $J G B / B M$ 62, KSA 5.81), o homem religioso (JGB/BM 58, KSA 5.75) e o santo (JGB/BM 47, 5.67), o espírito livre (JGB/BM 105, KSA 5.92), mas também “o oficialato nobre da marca" (JGB/BM 251, KSA 5.192) e "o tipo de maior êxito do novo germanismo" (JGB/BM 244, KSA 5.184). Apesar de uma "tipologia da moral" ainda estar por vir, o quinto capítulo aponta reiteradamente para tipos antagônicos e antagonismos tipológicos: numa "era de dissolução", avulta um "tipo mais fraco, que aspira ao repouso"; ao mesmo tempo, porém, surgem também os "homensenigma predestinados à vitória e à sedução, cujos mais belos exemplos são Alcibíades e César [...], e, entre os artistas, talvez Leonardo da Vinci"; "os dois tipos estão relacionados e se originam das mesmas causas" (JGB/BM 200, KSA 5.120; cf. JGB/BM 242, KSA 5.182) Este dois "tipos" opostos constituem uma constelação histórica, a "era de dissolução", por assim dizer um tipo de época, ao qual pertence também, mas não apenas, o presente europeu. Em "o que é nobre?", a oposição entre moral dos senhores e moral de escravos, formulada em termos "sociológicos", é central; aqui ainda não. Mesmo que se fale em uma "rebelião escrava na moral" (JGB/BM 195, KSA 5.116), tudo que é dito aqui numa terminologia "histórico-naturalista" e mesmo zoológica gira em torno do "homem de rebanho", ao qual se opõem, à sua própria maneira, figuras como o "homem tropical", isto é, o "animal de rapina e homem de rapina" (JGB/BM 197, KSA 5.117) à la César Bórgia, ou os filósofos do futuro de Nietzsche.

(D) Em "contribuição à história natural da moral", o "rebanho" e seus instintos desempenham um papel muito mais relevante do que na Genealogia da moral. Sua primeira dissertação retoma o capítulo "o que é nobre?" e desenvolve de modo mais detalhado sobretudo a oposição estabelecida ali entre moral dos senhores e moral de 
Brusotti, M.

escravos. Por sua vez, as três dissertações da Genealogia deixam de lado intencionalmente, segundo a explicação do próprio Nietzsche, o instinto de rebanho como móbile da moral. A razão, porém, não é que Nietzsche teria abandonado o conceito. Ao contrário: o instinto de rebanho seria "o mais essencial" "primum mobile" e teve que ser preterido simplesmente por se tratar de uma noção "demasiadamente vasta". ${ }^{14}$ Nesse sentido, a diferença com relação ao quinto capítulo de Para além de bem e mal não deve ser sobrestimada e sobretudo não deve ser compreendida como uma diferença entre os métodos "história natural" e "genealogia".

Não é somente em "contribuição à história natural da moral" que o conceito de "rebanho" assume um lugar proeminente. A expressão é utilizada por Nietzsche desde sempre, ${ }^{15}$ com especial frequência, porém, somente a partir de A gaia ciência: com frequentes considerações acerca dos "homens de rebanho" (FW/GC 23, KSA 3.395) e dos "instintos de rebanho" (FW/GC 328, KSA 3.555), esse escrito se distingue, num importante aspecto, de Aurora, cuja crítica à moral ainda não trabalha com esses conceitos. ${ }^{\mathbf{1 6}}$ Conjecturas evolucionistas acerca dos primórdios animalescos da moral e considerações sobre as "sociedades animais" de fato já

$14 \mathrm{Na}$ verdade, a terceira dissertação discute repetidamente a relação tensa entre o sacerdote acético e seu "rebanho". Mas, segundo Nietzsche, as três dissertações não podiam tratar de cada "primum mobile" "daquela formação complexa que se chama moral", e "o mais essencial ("o instinto de rebanho'), teve de ser momentaneamente deixado de lado por ser demasiadamente vasto" (Nietzsche a Overbeck, 4 de Janeiro de 1888; KSB 8, 224). Cf. sobre isso BRUSOTTI, Marco. Die "Selbstverkleinerung des Menschen" in der Moderne. Studie zu Nietzsches Zur Genealogie der Moral. In. Nietzsche-Studien 21, Berlin/New York: de Gruyter, 1992, especialmente p. 106s. (nota 45$)$.

15 "Desenvolvimento da zoologia. / Que o homem existe como animal de rebanho é comprovado pela estatística." (Nachlass/FP 29 [149], KSA 7.695). Cf. VM/OS 233, KSA 2.485.

16 À época de A gaia ciência, Nietzsche ainda não conhecia Francis Galton: suas considerações de então sobre o instinto de rebanho se orientavam mais por autores como Alfred Espinas e Georg Heinrich Schneider. O autor de Para Além de bem e mal, ao contrário, está familiarizado com as concepções de Galton. Sobre essa leitura, cf. HAASE, Marie-Luise. "Friedrich Nietzsche liest Francis Galton”. In. Nietzsche-Studien 18, Berlin/New York: de Gruyter, 1989, p. 633-658.

34 Cad. Nietzsche, Guarulhos/Porto Seguro, v.37, n.1, p. 17-43, 2016. 
aparecem anteriormente; mas é a partir de 1881 que se concentram as reflexões sobre o rebanho como o contexto "histórico-natural" no qual nossos impulsos foram vagarosamente "cultivados", em parte já previamente ao surgimento do homem enquanto tal: "Nossos impulsos e nossas paixões foram cultivados por enormes períodos de tempo em associações sociais e clãs (anteriormente em rebanhos de primatas)" (Nachlass/FP 11 [130], KSA 9.487). Em A gaia ciência, lemos: "Moralidade é o instinto de rebanho no indivíduo" (FW/ $G C$ 116, KSA 3.474). De acordo com essa concepção, uma moral expressa "necessidades de uma comunidade, de um rebanho", "as condições para a preservação de uma comunidade" (FW/GC 116, KSA 3.474). Pode-se supor que, também aqui, "rebanho" e "instinto de rebanho" não são concebidos de modo (meramente) imagético. Também em Para além de bem e mal, "clãs, comunidades, tribos, povos, Estados, Igrejas" não são "rebanhos de homens" (JGB/BM 199, KSA 5.119) num sentido meramente metafórico, mesmo que aqui as explicações histórico-naturalistas cedam lugar frente aos insultos artísticos em jargão zootécnico.

Para além de bem e mal retoma a tese de $A$ gaia ciência: "em questões morais o instinto, ou a 'fé', como dizem os cristãos, ou o 'rebanho', como digo eu, triunfou até agora" (JGB/BM 191, KSA 5.112). Segundo essa tese, "o velho problema [...] de 'fé" e "saber" pode ser reformulado como problema de "instinto e razão" (JGB/BM 191, KSA 5.112), isto é, como problema do domínio do instinto de rebanho sobre a razão individual. Anteriormente, o quinto capítulo havia explicado a obediência frente a mandamentos morais arbitrários através do "imperativo moral da natureza" (JGB/BM 188, KSA 5.108); então, ele oferece ainda uma segunda explicação históriconaturalista: mediante o "instinto gregário da obediência" (JGB/BM 199, KSA 5.119). A "necessidade" de obediência, que lentamente se originou nos "rebanhos de homens" e hoje é provavelmente inata, constitui, assim, "uma espécie de consciência formal que diz: "vc 
Brusotti, M.

deve absolutamente fazer isso, e absolutamente se abster daquilo', em suma, "você deve" (JGB/BM 199, KSA 5.119). Essa consciência busca "dar um conteúdo à sua forma" (JGB/BM 199, KSA 5.119e, também aqui, um conteúdo bastante aleatório. A concepção de Nietzsche é absolutamente distinta daquela de Kant, na medida em que, nessa "consciência formal", se mostra o domínio do instinto gregário sobre a razão individual.

(E) Em Para além de bem e mal, é sobretudo um tipo de moral que é derivada do rebanho, a assim chama "moral de rebanho", e Nietzsche considera que esta é tanto moral do homem primitivo quanto $a$ moral europeia atual. Ele afirma que "no tocante aos principais juízos morais a Europa se pôs de acordo" (JGB/BM 202, KSA 5.124). O quinto capítulo, em seu início, contrapõe a este consenso fundamental a pluralidade das morais que realmente existiram e, ao final, a pluralidade das possíveis futuras morais: "Moral é hoje, na Europa, moral de animais de rebanho: - logo, tal como entendemos as coisas, apenas uma espécie de moral humana, ao lado da qual, antes da qual, depois da qual muitas outras morais, sobretudo mais elevadas, são ou deveriam ser possíveis" (JGB/BM 202, KSA 5.124). Segundo Nietzsche, não podemos perder de vista "quantas vezes o tipo homem já defrontou decisões misteriosas e caminhos novos" e, sobretudo, "como o homem está ainda inesgotado para as grandes possibilidades" (JGB/BM 203, KSA 5.126). Recentemente, em tempos de emergentes e possíveis tecnologias de aprimoramento, tenta-se avaliar novamente o sentido, expresso aqui, para novas possibilidades do humano ou o interesse "transhumanista" de Zaratustra. Apesar disso, essas visões do futuro permanecem altamente problemáticas. As tentativas planetárias mencionadas acima são assunto do "filósofo do futuro", já anunciado em "o espírito livre" (JGB/BM 42, KSA 5.59). Estes "novos filósofos" devem estar em condições de estimular valorações opostas e tresvalorar e transtornar "valores eternos' (JGB/BM 203, KSA 5.126). Estes "homens do futuro, que 
atam no presente o nó e a coação que impõe caminhos novos à vontade de milênios", têm a tarefa de "ensinar ao homem o futuro do homem como sua vontade, dependente de uma vontade humana, e preparar grandes empresas e tentativas globais de disciplinação e cultivo, para desse modo pôr um fim a esse pavoroso domínio do acaso e do absurdo que até o momento se chamou 'história"' (JGB/ BM 203, KSA 5.126).

O procedimento experimental, planejado e global destes filósofos do futuro que Nietzsche designa, entre outras coisas, como "líderes" e "comandantes" (JGB/BM 203, KSA 5.126), está confrontado não somente com uma história abandonada ao acaso. Como veremos em seguida, a conclusão fortalece a alternativa. Um aforismo posterior estabelece uma analogia entre o processo no qual um tipo é "fixado", isto é, se torna "firme e forte", e o nascimento de uma espécie. Para Nietzsche, que, assim como inúmeros autores relevantes da época, acredita na transmissão de caracteres adquiridos, os dois casos não são tão diferentes; e todo o aforismo 262 de Para além de bem e mal se baseia nesse suposto paralelo, mas sem se expressar de modo mais assertivo acerca de sua natureza. Assim, Nietzsche, que pretende extrair ensinamentos a partir "das experiências de criadores", contrapõe à "degeneração" e ao "desvio" a "variação" "rumo ao mais sutil, mais raro e elevado" (JGB/BM 203, KSA 5.126). $\mathrm{O}$ aforismo 203, porém, não se expressa quanto à questão se um novo tipo é realmente "cultivado" como uma nova espécie. Mas ele visa uma oposição semelhante àquela entre "degenaração" [Entartung] e "desvio" [Abartung] (JGB/BM 203, KSA 5.126): por um lado, temos a "degeneração global do homem" abominada por Nietzsche, "essa degeneração e diminuição do homem, até tornar-se o perfeito animal de rebanho"; por outro, o filósofo chama a atenção a "tudo aquilo que [...] ainda se poderia cultivar de dentro do homem" (JGB/BM 203, KSA 5.126). Os dois cenários do futuro não são estranhos ao leitor do Zaratustra: trata-se, com efeito, de uma variante "histórico- 
Brusotti, M.

naturalista" da decisão, reivindicada no "Prólogo de Zaratustra", entre o último homem e o além-do-homem. Note-se: o lugar do além-do-homem, do qual não se fala mais em Para Para Além de bem e mal, é assumido aqui pelo novo "tipo" homem (ou: o próprio homem é um "tipo" com possibilidades inesgotadas). Por sua vez, o homem diminuído e degenerado até tornar-se "o perfeito animal de rebanho" é, agora, no vocabulário "histórico-naturalista", o "último homem" do "Prólogo de Zaratustra". Com a decisão reivindicada aqui se encerra o quinto capítulo, que, desse modo, encontra-se tensionado entre duas "tarefas": ele é introduzido com a advertência, direcionada à autointitulada "ciência da moral", de que é preciso abandonar finalmente as ilusórias ambições de fundamentação e dedicar-se pela primeira vez à tarefa mais modesta de uma descrição da moral. Por outro lado, o que constitui o encerramento e o horizonte do capítulo é uma ambicionada variante "histórico-naturalista" da tarefa prática estabelecida em Assim falou Zaratustra.

\section{Contribuição à história natural do espírito livre}

A concepção de uma história natural do espírito livre e do homem superior está ligada a muitos aforismos de Para além de bem e mal, não somente do quinto capítulo. Alguns anos antes, Heinrich Köselitz havia escrito a Nietzsche que "mesmo o filósofo mais íntegro [...], por exemplo, quando escreve uma história natural do gênio, pinta a si mesmo sem qualquer cerimônia [ganz ungeniert] (Heinrich Köselitz a Nietzsche, 18 de julho de 1879, Nr. 1213a, in KGB II $7 / 3,1,16)$. Para além de bem e mal vê em toda grande filosofia um autorretrato do filósofo em questão, e um autorretrato inconsciente (JGB/BM 6, KSA 5.19). Também e especialmente a "história natural do espírito livre" e "do homem superior", que Nietzsche apresenta momentaneamente como o tema que abrange todo o escrito em gestação, é, sem dúvida, um autorretrato não inteiramente inconfesso. 
Nos trabalhos preliminares correspondentes, a "história natural" representava o todo, o livro em desenvolvimento foi concebido (também) como uma dissertação histórico-naturalista, e o capítulo “o que é nobre?", por exemplo, constituía uma seção dessa "história natural" (KGW I 8, 173; cf. Também KGW I 8, 174; cf. Nachlass/FP 2 [41], 2 [43]; KSA 12.82s.). O filósofo pretendia, por assim dizer, escrever uma história natural de si mesmo: o intuito principal era uma história natural do espírito livre Nietzsche, do homem superior Nietzsche, mesmo que não somente do "senhor Nietzsche" $(F W / G C$, Prólogo, 2, KSA 3.347). Esse empreendimento histórico-naturalista autocentrado já prefigura a próxima publicação após Para além de bem e mal, os prefácios de 1886-1887 para a nova edição de seus escritos. O ciclo de prefácios poderia igualmente levar o título "contribuição à história natural do espírito livre". O aforismo 230 de Para além de bem e mal manifesta a intenção de "retraduzir o homem de volta à natureza" e tornar novamente reconhecível o "eterno texto básico homo natura" (JGB/BM 230, KSA 5.167), soterrado sob interpretações metafísicas. ${ }^{17} \mathrm{O}$ homo natura como 'eterno' texto básico, o filósofo nietzschiano como filólogo que finalmente o restabelece e o retraduz, a partir de uma transposição pervertida, de volta ao texto original: este complexo de imagens que se sobrepõem e se cruzam parcialmente contém uma assimetria fundamental entre um texto natural e suas interpretações sobrenaturais. Esta assimetria, porém, não pode ser sobre-interpretada: Nietzsche não considera a si mesmo como um

17 No lugar de "eterno texto homo natura" (JGB/BM 230, KSA 5.167) consta, num primeiro esboço, simplesmente "texto natural 'homem"” (KGW IX, 1, 21). Para uma análise da gênese do aforismo 230, na qual as teses sugeridas na sequência são atestadas, cf. BRUSOTTI, Marco. “der schreckliche Grundtext homo natura". Texturen des Natürlichen im Aphorismus 230 von Jenseits von Gut und Böse, In. BORN, Marcus Andreas/ PICHLER, Axel (Hrsg.): Texturen des Denkens. Nietzsches Inszenierung der Philosophie in Jenseits von Gut und Böse, Berlin/Boston: de Gruyter, 2013, p. 259-278. Sobre o aforismo 227 de Para além de bem e mal e para uma comparação com A gaia ciência 127, cf. BRUSOTTI, Marco Die Leidenschaft der Erkenntnis. Philosophie und ästhetische Lebensgestaltung bei Nietzsche von Morgenröthe bis Also sprach Zarathustra, Berlin/New York: de Gruyter, 199, p. 673ss. 
Brusotti, M.

leitor capaz de um acesso não-interpretativo a um "eterno texto básico". Nesse sentido, a metáfora pode induzir ao erro, mas ela representa, essencialmente, a eliminação dos diversos erros da antropologia metafísica e a postura que, nesse contexto, é exigida do homem do conhecimento. Nietzsche demanda "que no futuro o homem se coloque frente o homem tal como hoje, endurecido na disciplina da ciência, já se coloca frente à outra natureza, com intrépidos olhos de Édipo e ouvidos tapados como os de Ulisses" (JGB/BM 230, KSA 5.167), surdo frente aos cantos de sereia metafísicos de uma origem sobrenatural: do homem em geral, mas também das próprias virtudes.

Aquele que deve, antes de tudo, ser retraduzido de volta à natureza é o próprio homem do conhecimento. "Nossas virtudes", como é o título do sétimo capítulo, é lícito chamá-las de virtudes? A honestidade é a "última virtude" (KGW IX 2, 14), a virtude dos "espíritos livres", "a única que nos resta", "nossa virtude, da qual não podemos escapar" (JGB/BM 227, KSA 5.162). Esses "espíritos livres, muito livres" (JGB/BM 230, KSA 5.167), têm eles o direito de chamar de "honestidade" a única virtude que lhes resta? Também ela pertence aos "maus" impulsos "rebatizados"; não seria então preferível rebatizá-la mais uma vez? Não seria melhor que os espíritos livres dessem àquilo que os distingue um outro nome?

$\mathrm{O}$ aforismo 230 os alerta a não atribuir a si mesmos uma "extravagante honestidade" (JGB/BM 230, KSA 5.167): a palavra "honestidade" não pertence ela mesma às muitas "interpretações e conotações vaidosas e exaltadas" (JGB/BM 230, KSA 5.167) que impedem nosso acesso ao homo natura? Aquela postura audaciosa, portanto, deve ser mantida pelo homem conhecimento sobretudo na tarefa de retraduzir a si mesmo de volta à natureza. A "história natural" é uma investigação das morais existentes até então, mas não apenas; pois uma moral que, no tempo presente de Nietzsche, somente se anuncia e que, na verdade, pertence ao futuro, seria igualmente objeto da consideração histórico-naturalista: a moral

$40 \mid$ Cad. Nietzsche, Guarulhos/Porto Seguro, v.37, n.1, p. 17-43, 2016. 
pós-moralista, tal como ela deve ser personificada pelos espíritos livres, muito livres, pelos quais Nietzsche anseia.

\begin{abstract}
Beyond Good and Evil, especially the Fifth Book, is a key text to access the Nietzschean program of a "natural history of morals". In contrast to the modern project of grounding morality, which has characterized the supposed "Science of Morals" and was advocated by the majority of the German moral philosophers until then, Nietzsche proposes here, on one hand, as the first and immediate task that of collecting ethnographic and historic materials through a comparative analysis of many morals; on the other hand, this first task should be done as a preparation for a typology of Morals, one which would give us "a clear idea of the recurring and more common forms of these living crystallizations". This renewing of the Science of Morals is guided by the idea of translating man back again into nature, so that these various moral crystallizations, composed from such a heterogeneous and historically situated material, could be psychologically classified and interpreted as a sign-language of emotions. In this sense, historical and psychological-natural aspects converge around a central theme: the herd moral and them main instincts expressed by it. To this moral, Nietzsche opposes his problematic project of disciplining and cultivating a superior type of man.
\end{abstract}

Keywords: moral - science - typology - history - homo natura

\title{
Referências bibliográficas
}

BRUSOTTI, Marco. Die "Selbstverkleinerung des Menschen" in der Moderne. Studie zu Nietzsches Zur Genealogie der Moral. In. Nietzsche-Studien 21, Berlin/New York: de Gruyter, 1992, p. 81-136.

. Die Leidenschaft der Erkenntnis. Philosophie und ästhetische Lebensgestaltung bei Nietzsche von Morgenröthe bis Also sprach Zarathustra, Berlin/New York: de Gruyter, 1997.

. "Europäisch und über-europäisch". Nietzsches Blick aus der Ferne. In.

Tijdschrift voor Filosofie 66, 2004, p. 31-48.

Cad. Nietzsche, Guarulhos/Porto Seguro, v.37, n.1, p. 17-43, 2016. |41 
Brusotti, M.

"Naturalismus? Perfektionismus? Nietzsche, die Genealogie und die Wissenschaften". In. HEIT, Helmut/ABEL, Günter/BRUSOTTI, Marco (Hrsg.). Nietzsches Wissenschaftsphilosophie: Hintergründe, Wirkungen und Aktualität, Berlin/Boston: de Gruyter, 2011, p. 91-112.

"der schreckliche Grundtext homo natura". Texturen des Natürlichen im Aphorismus 230 von Jenseits von Gut und Böse, In. BORN, Marcus Andreas/ PICHLER, Axel (Hrsg.): Texturen des Denkens. Nietzsches Inszenierung der Philosophie in Jenseits von Gut und Böse, Berlin/Boston: de Gruyter, 2013, p. 259-278.

DARWIN, Charles. Die Abstammung des Menschen und die geschlechtliche Zuchtwahl. Dritte gänzlich umgearbeitete Auf lage, 2 Bde., Stuttgart: E. Schweizerbart'sche Verlagshandlung, 1875.

DURKHEIM, Émile. "La science positive de la morale en Allemagne", In. Revue philosophique 24, 1887, 33-58, 113-142, 275-284.

HAASE, Marie-Luise. "Friedrich Nietzsche liest Francis Galton". In. NietzscheStudien 18, Berlin/New York: de Gruyter, 1989, p. 633-658.

HELLWALD, Friedrich Anton Heller von. Culturgeschichte in ihrer natürlichen Entwickelung bis zur Gegenwart. Augsburg: Butsch, 1875.

. Die Erde und ihre Völker. Ein geographisches Hausbuch, 2. Auf 1., 2 Bde., Stuttgart: Francke, 1877-1878.

. Naturgeschichte des Menschen, Stuttgart: Francke, 1882.

LECKY, William Edward Hartpole. Sittengeschichte Europas von Augustus bis auf Karl den Grossen, Bd. 1, Leipzig/Heidelberg: C.F. Winter'sche Verlagshandlung, 1879.

NIETZSCHE, Friedrich. Sämtliche Werke. Kritische Studienausgabe, Berlim: Walter de Gruyter \& Co., 1967/1978. 15 vols. (Organizada por Giorgio Colli e Mazzino Montinari).

. Além do bem e do mal. Trad. de Paulo César de Souza. São Paulo: Cia. das Letras, 1999.

- A gaia Ciência. Trad. de Paulo César de Souza. São Paulo: Cia. das Letras, 2001 .

42 | Cad. Nietzsche, Guarulhos/Porto Seguro, v.37, n.1, p. 17-43, 2016. 
TREIBER, Hubert. Zur Genealogie einer "science positive de la morale en Allemagne". Die Geburt der "r(é)ealistischen Moralwissenschaft" aus der Idee einer monistischen Naturkonzeption. In. Nietzsche-Studien 22, Berlin/ New York: de Gruyter, 1993, 165-221.

VAN TONGEREN, Paul. Die Moral von Nietzsches Moralkritik. Studien zu Jenseits von Gut und Böse, Bonn: Bouvier, 1989.

WUNDT, Wilhelm. Ethik. Eine Untersuchung der Thatsachen und Gesetze des sittlichen Lebens, Stuttgart: F. Enke, 1886.

Artigo recebido para publicação em 6/09/2015.

Artigo aceito para publicação em 8/11/2015. 